\title{
A Review of the Teaching Modalities Chosen by Faculty During the Global Pandemic
}

\section{Prof. Dani Fadda P.E., University of Texas at Dallas}

Dr. Fadda is Associate Professor of Practice in Mechanical Engineering. His background includes two decades of engineering practice in the energy industry where he has held numerous positions. Dr. Fadda has worked in product research and developed patented products for chemical, petrochemical, and nuclear applications. He is an ASME Fellow and a Professional Engineer.

\section{Dr. Oziel Rios, University of Texas at Dallas}

Dr. Oziel Rios earned his Ph.D. in mechanical engineering from the University of Texas at Austin in 2008 where his research focused on design of robotic systems with an emphasis on kinematic and dynamic modeling for analysis and control. Dr. Rios teaches the first-year and CAD courses in the Mechanical Engineering Department at the University of Texas at Dallas. Dr. Rios has also taught kinematics and dynamics of machines and graduate-level CAD courses. Dr. Rios' research and teaching interests include: robotics, design, kinematics and dynamics of machines and engineering education.

\section{Roopa Vinay, University of Texas at Dallas}

Roopa Vinay works an eLearning Manager at the University of Texas at Dallas. She oversees faculty training and support in educational technology applications. She developed an online certification program to help faculty transition from classroom to online teaching. During the 2020 pandemic she designed and coordinated a University-wide training effort to help faculty teach remotely. She has worked with subject matter experts across disciplines to develop academic courses, certification programs, and open-source learning materials. Her background is in instructional design, LMS administration, multimedia production, and student engagement systems. 


\title{
A Review of Teaching Modalities Chosen by Faculty During the Global Pandemic
}

\begin{abstract}
Universities, worldwide, are managing their course offerings during the coronavirus pandemic in different ways and numerous factors are considered when selecting an appropriate teaching modality. In this paper, a research question is posed as follows: how do faculty members prefer to teach during the pandemic and what are the implications? Data is provided from the engineering and computer science faculty members at The University of Texas at Dallas, where faculty are individually offered a choice among five different teaching modalities. The results are used to quantify our faculty's selection and explain reasons for selecting a particular teaching modality. The required preparation, and the support offered by the university to the faculty during the pandemic are also addressed. Half the faculty, who taught virtual classes, consider the student's performance on assessments comparable to the performance of students during previous semesters when the class was given in-person. A quarter considers the student's performance better and a quarter considers it worse. Beyond the pandemic, the majority of the engineering and computer science faculty prefer flexibility between the classroom and remote teaching. Otherwise, they prefer teaching in the office over working from home.
\end{abstract}

Introduction

The coronavirus pandemic has affected educational institutions around the whole world and the reaction to its contagious spread is perceived differently by different universities. Regardless, seating a large number of students physically in a traditional classroom is not considered safe during the pandemic and teaching modalities that minimize spread of the virus are adopted. While a transition to virtual learning can eliminate the spread of the virus, such transition cannot be taken lightly by everyone. A report by Allen and Seaman [1] indicates that institutions with online offerings in 2014 to 2015 are just as positive about it as ever, but those who have no online offerings say that it will not be part of their plans for the future. Moreover, academic leaders at institutions with online offerings have consistently held a more favorable opinion of the learning outcomes for online education than those at institutions with no offerings. Even after a decade of substantial growth in the number of schools with distance learning offerings and the number of students taking these courses, the level of skepticism among faculty has remained very high according to the authors.

The decision to offer virtual classes during the pandemic is taken prudently at our university since most classes are traditionally offered in a face-to-face format. Specifically, our 2018-2019 Educational Technology Services (ETS) Annual Report [2] states that Online and Blended credit hours made up only $6.89 \%$ and $1.46 \%$, respectively, of the total credit hours offered at the university. While most classes at our university are traditionally offered in a face-to-face format, a Learning Management System (LMS) is implemented in all classes. An Educational Technology Services (ETS) team of professionals support the LMS and its infrastructure. This infrastructure 
includes multiple video streaming, video conferencing, and video recording platforms. The university also offers comprehensive training for faculty to achieve online teaching certification and to develop online classes [3,4]. This training comes with numerous resources, including software for recording videos, studio for recording lectures, infrastructure for streaming videos, and technical support. Overall, the university provides the infrastructure for developing virtual classes even though most faculty prefer in-person teaching.

During the summer of 2020, a survey was conducted by the academic senate and administered to the faculty of all departments in the university between June 8 and 11, 2020 [5], in preparation for the Fall 2020 semester. Faculty members were asked, in this survey, to present their preference to teach in one of the seven different categories shown in Table 1. The results of the survey are also shown in this table. The contact between faculty and students or between students is added in Table 1, where the first three categories require physical contact. The Online category is completely virtual and includes no physical contact. The other categories were selected by faculty who could go either way. The main reported reasons influencing the faculty's decisions are related to pedagogical reasons and equipment limitations, coupled with their tolerance of the pandemic and its effect on the students, faculty, and the community [5].

Table 1, Categories and Results for the Academic Senate's University-Wide Faculty Survey [5]

\begin{tabular}{|l|c|c|}
\hline Survey Categories & Results & Contact \\
\hline In person & $8.34 \%$ & Physical \\
\hline Hybrid & $7.76 \%$ & Physical \\
\hline In person and hybrid & $5.75 \%$ & Physical \\
\hline In person and online & $6.76 \%$ & Either way \\
\hline Online and hybrid & $10.93 \%$ & Either way \\
\hline All & $21.29 \%$ & Either way \\
\hline Online & $39.13 \%$ & Virtual \\
\hline
\end{tabular}

Before the start of the Fall semester of 2020, the teaching modalities offered at our university were finalized and named as: 'Traditional Classroom/Laboratory,' 'Blended Hybrid,' 'Flexible mode,' 'Remote Virtual,' and 'Online.' These are described below, and faculty were given a choice among these modalities to best suit their courses.

All modalities must include video recordings of the lectures using cameras installed in the classrooms to allow asynchronous viewing of the lectures with ADA compliant subtitles and transcripts for students who cannot be on campus due to the pandemic. The traditional, the blended hybrid, and the flexible modalities include face-to-face instruction with social distancing and personal protective equipment in mind. The traditional and blended hybrid modalities utilize classrooms where social distancing measures can be implemented. The flexible modality allows a small number of alternating students to be physically present in the classroom while others attend synchronously online. The remote virtual and online modalities are performed online synchronously and asynchronously, respectively. They exclude any face-to-face instruction. 
In this paper, we seek to answer: how do faculty members prefer to teach during the pandemic and what are the implications? The research is focused on the engineering and computer science faculty at our university because they individually select the teaching modality that fits their class. The faculty included in this work teach all classes and labs in the engineering and computer science curriculum. Their preferred teaching modality is obtained and factors behind their selection are described. The faculty's assessment of student's performance is discussed and the faculty's preference for the future (beyond the pandemic) are presented. We expect that the results presented herein can be generalized to engineering and computer science schools at other similar universities, but more work is needed to evaluate their reproducibility at other universities.

\section{The Choice by ECS Faculty}

A short survey with eleven (11) questions is developed and deployed to all engineering and computer science faculty at our university. The questions are shown in Table 2 and responses from seventy-eight (78) faculty members are available (collected between January 28 and February 8, 2021, during the Spring semester of 2021).

The responses of only those who agree to Question 1 are recorded. The response to Question 2 of the survey, regarding the chosen modality, is plotted in Fig. 1 using orange-colored bars. Also shown in Fig. 1 are the modalities reported in the university's public information system, Course Book [6], for the Spring of 2021 and the Fall of 2020 [7]. Specifically, all the engineering and computer science courses are downloaded and sorted by the teaching modality. The number of faculty members teaching in each modality are counted and the percentages are reported in Fig. 1. The total number of faculty members teaching classes listed in Course Book is 270 per semester (average for Fall 2020 and Spring of 2021) in the school of engineering and computer science. Analysis of this figure is presented below, based on the faculty's response to Questions 3 of the survey.

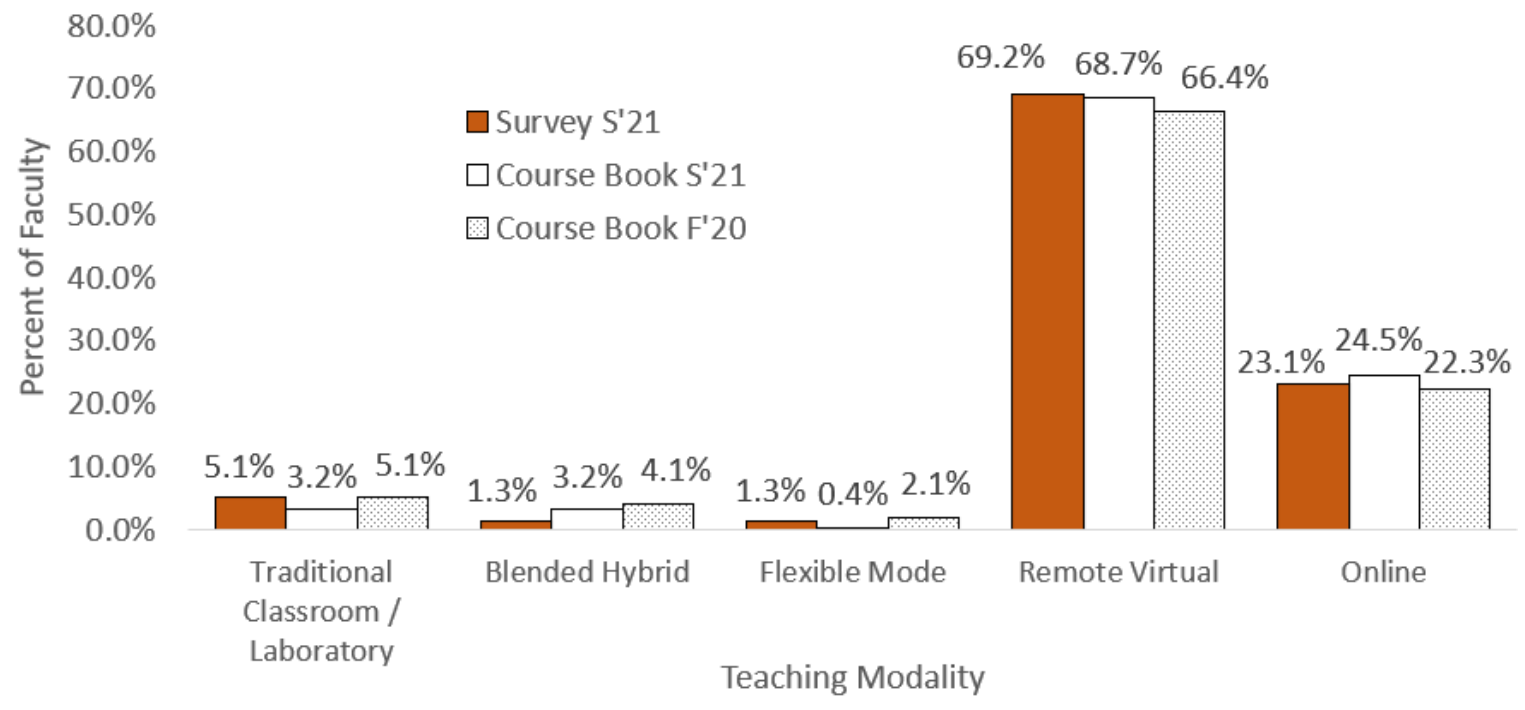

Fig. 1, Faculty Selection for the Fall of 2020 and Spring of 2021 in the School of Engineering and Computer Science 
Table 2, Survey Questions

1. A statement by the Institution Review Board (IRB) is provided and faculty are asked to exit the survey or click "I Agree" to begin.

2. Which teaching modality did you choose?
a. Traditional
b. Hybrid
c. Flexible
d. Remote/Virtual
e. Online

3. Why did you choose this modality?

4. What changes did you make to your course when moving to virtual/ online?

5. What helped your teaching experience in the changed modality? How did you get help?

6. What hindered your teaching experience?

7. What was your students' experience taking the course in a remote/ virtual modality?

8. How did students do on assessments (exams, homework, quizzes) in the remote/ virtual modality?
a. Much better than in-person
b. Better than in-person
c. Same as in-person
d. Worse than in-person
e. Much worse than in-person

9. Given a choice, will you continue to use this modality after the pandemic? Why?

10. Will you re-use any of your recordings in future classes?
a. Yes
b. No

11. After the pandemic, how would you want to return to the workplace?
a. I want to be in the office
b. I want to be at home
c. Flex between home and office

It is important to note at first that the difference between the survey results and the Course Book data, shown in Fig. 1, for the Spring of 2021 are strictly less than 2\%. This agreement supports the validity of the survey data to represent the faculty of engineering and computer science at our university.

Next, the percentage of faculty members teaching in modalities that require in-person contact (Traditional Classroom/Laboratory, Blended Hybrid, and Flexible Mode) is small, as compared to other modalities that do not require in-person contact (Remote Virtual and Online). This is qualitatively consistent with the data shown in Table 1, in terms of the bias towards modalities that do not require in-person contact. This bias in Fig. 1 is due to the engineering and computer science faculty's concern to protect their health, the health of the students, and the health of the community during the pandemic. Their concern is legitimate according to the findings of Leidner et al. [8]. Specifically, a faculty member, teaching in the Online modality, wrote: "I wanted all the class to 
be complete and available for my students in case I got sick with the virus." Others who teach remotely wrote: "I care for my 90-year-old mother on the weekends, my husband is also at high risk, so I did not want to expose my loved ones to the coronavirus." Another faculty member wrote: "To avoid exposure to students who may not be practicing as rigorous a safety regimen as Ifeel necessary in the pandemic situation."

Contrarily, faculty members who taught in the Traditional modality insist it is the best way and write: "It fits me better" or I use it to "better connect with students and provide students with more options to learn" or "since it is well known that more than 50\% of communication is nonverbal communication, I think a lot of teaching quality is lost through online teaching." Additionally, those who taught in the Flexible modality write that their "students attended online synchronized, offline, and in-person. Course has extensive amount of in-class technology demonstrations." Other faculty chose the Blended Hybrid modality "because I have some students, only a few, who either want to come to class or are required by visa and loan conditions that they have to come to class."

When comparing the university's course book data (plotted in Fig. 1) between the Fall of 2020 and the Spring of 2021, a relative consistent decrease is observed among the three modalities requiring face-to-face contact in 2021. This is mainly because video recordings of the class activities are required for all modalities. The recordings are provided to allow asynchronous viewing of the class work by students who are at high health risks (themselves or family members). Many students watched the lecture at home instead of coming to class, leaving the professor in a large class with only a few students. A faculty member who transitioned from the Traditional to the Online modalities wrote: "I taught these same two sections last semester using the Traditional mode and I had two sections with 80 students each. When I showed up to class, about 10 students would be present."

Faculty's Preparation to Teach Virtually

The Educational Technology Services (ETS) offered training sessions to all faculty at our university using Black Board Collaborate at the start of the pandemic. ETS also provided support sessions for using Microsoft Teams and Microsoft Stream so faculty could take advantage of the automatically generated closed captions. Furthermore, the university offered software for creating video recordings and, even when stretched very thin at times, the ETS team continuously offered help to equip and prepare the faculty throughout the duration of the pandemic.

A group of seventeen (17) faculty mentors with experience in teaching virtually and the ETS staff also held open weekly or bimonthly meetings that spanned 1 to 1.5 hours on Friday afternoons throughout the pandemic. Some of these meetings included presentations of specific tools, such as Camtasia, Honorlock, eLearning, Microsoft Stream, Microsoft Teams, Blackboard Collaborate, Respondus, etc. Others were open sessions where faculty posed questions and the mentors, together with the ETS staff, help with providing demonstrations and answers. 
The Center of Teaching and Learning (CTL) also posted support information in a course where all faculty are enrolled. This information was updated often and included education research findings, show and tell, and successful implementations by colleagues.

The Office of Information Technology (OIT) offered help with managing secure logins for the faculty and the students. This was necessary since students need remote access to the lab computers for doing lab work and homework assignments.

With these resources in place, among many others, the faculty who selected Remote/Virtual or Online updated their courses and offered them virtually. Questions 4, 5, and 6 of the survey address the faculty's preparation for teaching in the Remote/Virtual and the Online modalities during the pandemic. These questions are also used to identify items that helped or hindered the faculty's ability to teach. The results of the survey confirm the vast difference between teaching in the Remote/Virtual versus the Online modalities.

The Remote/Virtual modality is one that is very similar to in-person teaching. To explain their preparation for teaching in this modality in the survey, the faculty express that the learning curve is reasonable. One faculty member wrote in the survey about the preparation for the transition as "none that I can think of. It wasn't difficult." Another faculty member wrote: "Not much. I used to teach on my iPad even in the classroom, so everything is the same." However, some faculty with no prior experience with technology expressed frustration and felt alone at first. They relayed, in the survey, that they needed basic support during the start of the pandemic to find their class in Teams and record their live session instead of the advanced topics that were often discussed.

What helped the faculty in the transition to the Remote/Virtual modality, as found in the survey, is: "Supportfromthe Office of Information Technology" in addition to "Online tutorials" that were prepared by the university's ETS department. Faculty also wrote that they received help by "Speaking with colleagues, writing to eLearning and Teams help, and looking for solutions on my own." Several faculty members wrote messages mirroring "I got most of my help/assistance from a teaching faculty in my department. The Center of Teaching and Learning resources were also of tremendous help." As for what hinders the teaching experience in this modality, several faculty members identify the "lack of interactions" and "less engagement." One faculty member identified this as "not being able to see students' faces to gauge pacing and level of understanding." Furthermore, "Switching between whiteboard and slides and checking for comprehension all slowed down the class and reduced the amount of material covered." Additionally, the availability of the lecture video for asynchronous viewing was brought up by several faculty members. One faculty member considered it a hinderance "since many students didn't come to the online classroom. This led to many more questions in e-mail even though the recordings were available." When dealing with labs, the faculty found new burdens, as "students needed a lot more help in an at-home setting versus in-person lab scenario." Other difficulties expressed in the survey are due to the Internet speed and other "technical problems with the technology tools - sudden session drop, freezes ... etc." 
The Online modality is quite different from in-person teaching and requires a significant level of preparation before the semester starts. Faculty who teach in this modality write that they "Recorded all the lectures in short pieces and loaded all the recordings on BOX and Stream. Developed complete eLearning modules." Streaming from both servers to the eLearning modules offers redundancy while Stream offers automatically generates subtitles. Another faculty member used YouTube for hosting the videos and wrote: "Starting in the summer I created my own videos with Camtasia and put them on YouTube. YouTube does a good job with closed captioning, which helps foreign-born students. Based on stats, I can tell that students watch the videos more than once, which they can't do in a live lecture." Another faculty member wrote: "Lecture courses: not much (except recording vs live in-person lectures). Labcourses: I had to make major changes to the lab procedures to make them suitable for doing at home. Combination of simulation and hands-on work." Furthermore, "staying to the point in 10-15 minute videos require knowing exactly what you need to say." Once the videos are recorded, another faculty member wrote: "Extensive effort is required to create modules for these courses. I eliminated exams and increased the number of assignments and quizzes. I have required students to do virtual demos with graders to present their projects." Another faculty member wrote: "The whole course structure has been changed. Particularly, a live discussion session is included to actively facilitate students' learning."

As for the help received by faculty who taught in the Online modality, some faculty members had already taken the Online Certification Course at our university or at other places. Specifically, several faculty members wrote that they "underwent a training course." Another faculty member received help "From colleagues with more online experience. I wish I received a similar training when switching to the online modality." Another wrote: "The training sessions from eLearning team were helpful. Having discussions with colleagues were also helpful." The instructional design team (part of ETS) offered tremendous support and one faculty member wrote: "I had some help from the instructional design team on setting up the courses in eLearning. We met over teams." The faculty teaching in the Online modality were "Spending a lot of time before the semester started to carefully plan and setup things before the semester." The aspects hindering the teaching experience in the Online modality have multiple levels according to the survey results. Faculty who used this modality without prior mastery of the basic tools (eLearning, Microsoft Teams, Microsoft Stream, Camtasia, BOX, and others) had a very hard time understanding and using the help they were receiving during the start of the pandemic. One faculty member wrote: "Unfortunately, most of the training sessions were geared to people who already know all the basics of how to use MS Teams and concentrated on added features that, although very nice, were not helpful in getting to learn how to use the system for beginners." At a higher level, other faculty members faced difficulty in managing the courses due to "the effort to provide students a feeling of connection while transitioning to a disconnected mode of learning. It required enormous amounts of email communication with students" More effort is needed throughout the semester in "keeping students engaged, making them watch the entire video, and make sure they did get the main idea and concept."

A common issue encountered when using both virtual modalities (Remote/Virtual or Online) relate to proctoring during quizzes and exams. A faculty member wrote: "Reliable testing has become 
problematic" even though the university purchased a subscription to Honorlock [9] for online proctoring. The steps for setting up Honorlock are not trivial to faculty who are not fluent users of the learning management system. In some cases, proctoring was also performed by some faculty using the Microsoft Teams video conferencing throughout the exams.

Regardless of the teaching modality, when writing about what hindered the teaching experience, some faculty also shared, in the survey, their deep concern about the student's mental well-being during the period of social distancing. The faculty wrote about the difficulties in teaching while "coping with student emotions and reactions to the eLearning environment." More on the faculty's perception regarding the student's experience is presented next.

Student's Experience and Performance on Assessments

Within their answer to Question 7 of the survey about the student's experience, some faculty members teaching virtually recommend deploying a follow-up survey to the students and obtaining the student's feedback. Others provided feedback as follows regarding the perceived student experience.

Faculty who taught in the Online modality wrote: "Students have given mixed reviews. But I think students who are responsible enjoyed this modality." Others based their response on the course evaluations and wrote: "I received positive comments in my evaluations." or "Excellent. Highest evaluations ever. A higher than normal number of students emailed me to thank me for the wellrun course." Another faculty member who taught in the Online modality wrote: "Most of them seemed satisfied with the lecture courses. But they felt the labs were tougher to do remotely." Or "They were generally satisfied; the evaluation scores did not show any significant change."

Faculty who taught in the Remote/Virtual modality reported an overall neutral response with only some negative responses: "Students struggle to stay engaged." or "Many students find it hard to focus. Too many distractions on the computer." There were some positive responses as well: "Most seemed to really like it and even prefer it." However, the general theme from faculty who taught in the Remote/Virtual modality is: "It was practically the same just meeting online instead of a classroom."

The response to Question 8 of the survey, regarding the performance of students on assessments (exams, homework, quizzes) in the remote/virtual modality, is shown in Fig. 2. Half of the engineering and computer science faculty consider the student's performance in the virtual environment same as in-person. Twenty-five percent $(25 \%)$ say it is better or much better and twenty-four $(24 \%)$ say it is worse or much worse. Since $24 \%$ of the faculty retort that the students did not do as well in a virtual environment as previous in-person classes, more work is needed to support the faculty in delivering the education during the pandemics and the students in receiving the content, should the pandemic duration be further extended. It is encouraging, however, to see $25 \%$ of the faculty consider the students did better in the virtual environment. 


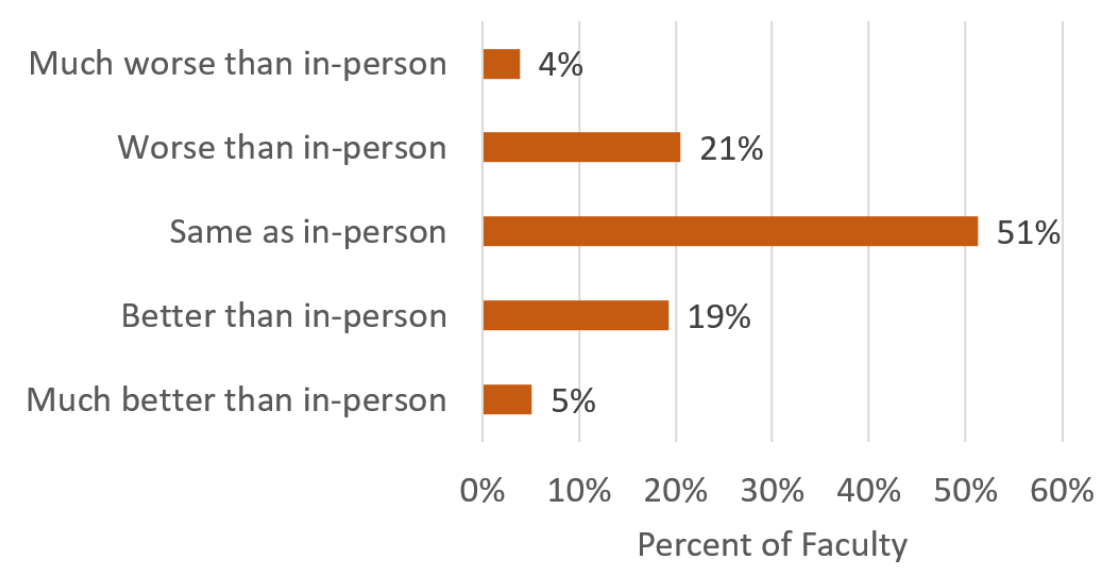

Fig. 2, Faculty's Response Regarding Student's Performance on Assessments (exams, homework, quizzes) During the Pandemic

The Future Beyond the Pandemic

The roll-out of vaccines, experienced while preparing this manuscript, brings hope of recovery from the pandemic. However, the pandemic will have a residual effect on the teaching preference of the faculty. Thirty-nine percent (39\%) and nineteen percent (19\%) of the faculty who taught in the Online modality and the Remote/Virtual modality prefer to continue with these modalities, respectively, according to their answer to Question 9. Forty-four percent (44\%) and sixty-five percent $(65 \%)$ of the faculty who taught in the Online modality and the Remote/Virtual modality prefer to stop using with these modalities, respectively. The remaining faculty members are open to continuing to teach remotely or in the classroom.

The responses from faculty who taught in the Online modality include: "Yes, I think I can develop more effective teaching with an online modality." Other answers include: "No, I rather get back to normal face-to-face but I will use the tools and videos to improve my student's experience in my in-person courses." Other answers include: "No, nothing is like being in the classroom live."

Responses from faculty who taught in the Remote/Virtual modality include: "Yes. I was infected with respiratory-related diseases a lot less since I taught in this modality. Minimizing close interactions with students is the primary reason for this." Contrarily, many answers include: "No, in-person seems to engage students better." or "No, for most classes. In-class is much better. I can walk around and look at what they're doing, see the looks on their faces, and make sure they are actually present."

The response to Questions 10 of the survey reveals that $55 \%$ of the engineering and computer science faculty who completed our survey intend to use some of the recordings developed during the pandemic in future classes.

Question 11, regarding the return to the workplace, was adopted from a survey by LinkedIn News [10], which was deployed to the general membership of LinkedIn from different industries 
worldwide. The response by the LinkedIn users and the response of the engineering and computer science faculty to our survey of Spring 2021 are plotted in Fig. 3. Even though the demographics are different, most responses consistently indicate a preference to work in a flexible mode between home and the office. The second and third choices are inconsistent between the results of our survey and the results of the LinkedIn survey. Only 5\% of engineering and computer science faculty want to continue working strictly from home as opposed to $27 \%$ of the LinkedIn users. Faculty seem to miss life on campus and their interaction with the students.

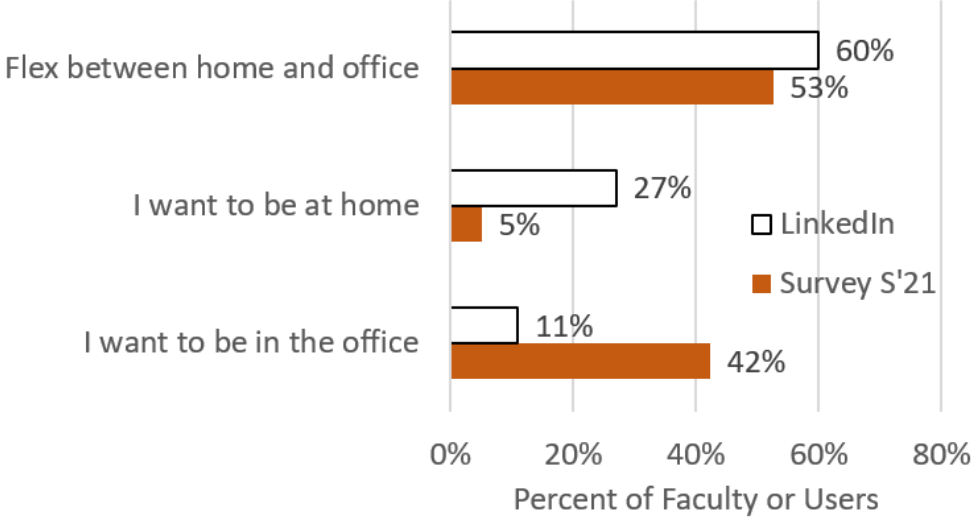

Fig. 3, Response of the Engineering and Computer Science Faculty and The LinkedIn Members [10]

\section{Summary}

In this paper, we explain how faculty members prefer to teach during the COVID-19 pandemic and the implications related to their preference. Data is provided based on the Jonsson School of Engineering and Computer science faculty members at The University of Texas at Dallas because these faculty members are offered a choice individually among five different teaching modalities. Over $66 \%$ and over $22 \%$ of the faculty selected the Remote/Virtual and the Online modalities, respectively. Minimal preparation prior to the first day of classes is needed to teach in the Remote/Virtual as compared to teaching in the Online modality. On average, the faculty considers the student's performance comparable to previous in-person offering of the class. Beyond the pandemic, the faculty wants flexibility in the future between working on campus and from home. If this option is not available, they prefer to work from the office and avoid working from home. Additional future work is needed to confirm the extent to which the results presented here can be reproduceable in other institutions.

\section{References}

[1] I. E. Allen and J. Seaman, "Online Report Card Tracking Online Education in the United States," Babson Survey Research Group and Quahog Research Group, LLC., 2016.

[2] The University of Texas at Dallas, "Educ ational Technology Services (ETS) Annual Report," Page 4, 2018-2019, https://dox.utdallas.edu/report31038

[3] Fadda, D. and Rios, O., 2019, "Online Computer Aided Design Class," 126th ASEE Annual Conference and Exposition, June 15 - 19, 2019, Tampa, Florida, USA 
[4] Fadda, D. and Vinay, R., 2019, “Teaching Computer Aided Design Online," Proceedings of the ASEE Gulf-Southwest Annual Conference, The University of Texas at Tyler, March 10-12, Tyler, Texas, USA.

[5] A. Venna, "Instructing face-to-face: Professors cite class participation, lec ture style as reasons in opting for in-person instruction modalities," The Mercury, July 27, 2020, https://utdmercury.com/instructing-face-to-face/

[6] Course Book, https://coursebook.utdallas.edu/

[7] D. Fadda, O. Rios, and R. Vinay, 2021, "Teaching Modalities During the COVID-19 Pandemic," Proceedings of the 2021 ASEE Gulf-Southwest Annual Conference, Baylor University, Waco, TX.

[8] AJ Leidner, V Barry, VB Bow en, et al., Opening of Large Institutions of Higher Education and County-Level COVID-19 Incidence - United States, July 6-September 17, 2020. MMWR Morb Mortal Wkly Rep2021;70:14-19. DOI: http://dx.doi.org/10.15585/mmwr.mm7001a4

[9] Honorlock proctoring: https://honorlock.com/

[10] LinkedIn News, October 2020, Survey regarding the users' preferred method for work after the pandemic. The results are based on 82,024 responses, https://ww w.linkedin.com/feed/update/urn:liactivity:6725376757366706176/ 